This paper has analyzed protective
Thatrials for timber building structures
materials
and established the need to devise reli-
able methods for studying the process of
water absorption by the surface of the con-
struction structure necessary for design-
ing new types of fire-retardant materials.
Therefore, it becomes necessary to deter-
mine the conditions for the formation of a
barrier for water absorption and to eluci-
date a mechanism for inhibiting the transfer
of moisture to the material. In this regard,
a mathematical model of the intensity of
water mass transfer when using a polymer
shell made of organic material as a coating
has been built, which makes it possible to
assess the effectiveness of the polymer shell
by the amount of water absorbed. Based
on the experimental data and theoretical
dependences, the intensity of absorption of
water by wood was calculated; and it has
been established that the protective coat-
ing reduces the amount of water absorbed
by more than 20 times. The results of deter-
mining the weight gain by a sample during
water exposure indicate an ambiguous
impact of the nature of protection on water
absorption. In particular, this implies the
presence of data sufficient for the qualita-
tive process of inhibition of moisture diffu-
sion; and detecting, on its basis, the point in
time when the drop in the coating's efficien-
cy begins. Analysis of the results of exper-
iments reveals that the maximum increase
in mass in the case of water absorption by
a non-treated sample of wood was $40 \%$
while the increase in the mass of wood sam-
ples treated with mixtures of oil and par-
affin was less than $28 \%$. At the same time,
the best protection is shown by a mixture
of oil with paraffin within $90 \div 95 \%$. Thus,
there are grounds to assert the possibility of
directed regulation of wood protection pro-
cesses through the use of polymer coatings
that can form a protective layer on the sur-
face of the material, which inhibits the rate
of absorption of water
Keywords: protective means, weight
gain of wood, wood surface treatment,
water absorption, polymer shell

\title{
ESTABLISHING REGULARITIES OF WOOD PROTECTION AGAINST WATER ABSORPTION USING A POLYMER SHELL
}

\author{
Yuriy Tsapko** \\ Corresponding author \\ Doctor of Technical Sciences, Professor* \\ E-mail: juriyts@ukr.net \\ Oleksandra Horbachova \\ $\mathrm{PhD}$, Associate Professor* \\ Serhii Mazurchuk \\ $\mathrm{PhD}$, Associate Professor*
}

Aleksi Tsapko

$\mathrm{PhD}$, Senior Researcher**

Department of Research of Quality and Conditions of Storage of oil

Products and Industrial Group of Goods

Ukrainian State Research Institute "Resource"

Kazymyra Malevycha str., 84, Kyiv, Ukraine, 03150

Kostiantyn Sokolenko

$\mathrm{PhD}$, Associate Professor

Department of Forestry

Bila Tserkva National Agrarian University

Soborna sq., 8/1, Bila Tserkva, Ukraine, 09117

Andrii Matviichuk

$\mathrm{PhD}$

V. I. Vernadsky National Library of Ukraine

Holosiivskyi ave., 3, Kyiv, Ukraine, 03039

*Department of Technology and Design of Wood Products National University of Life and Environmental Sciences of Ukraine

Heroiv Oborony str., 15, Kyiv, Ukraine, 03041

**V. D. Glukhovsky Scientific Research Institute

for Binders and Materials

Kyiv National University of Construction and Architecture

Povitroflotsky ave., 31, Kyiv, Ukraine, 03037

Received date 11.01.2021 Accepted date 04.02.2022 Published date 25.02.2022
How to Cite: Tsapko, Y., Horbachova, O., Mazurchuk, S., Tsapko, A., Sokolenko, K., Matviichuk, A. (2022). Establishing regularities of wood protection against water absorption using a polymer shell. Eastern-European Journal of Enterprise Technolo-

\section{Introduction}

Wood, as a building material, is widely used in construction and architecture due to its mechanical and operational properties. However, during operation, the stability of geometric dimensions and resistance to the external environment change, which leads to the need for additional treatment. The fact that protective treatment reduces the sensitivity of wood to moisture exposure and biological damage expands the scope of application of timber structures. The operational reliability and efficiency of wood protection depend on the quality and reactivity of the coating, as well as on the class of operating conditions of the facility where these materials are used. Protection of timber structures is also necessary for objects of mass stay of people, operated under different temperature conditions. An example is a construction of children's camps and recreation centers, which are often not heated. Or special-purpose facilities, such as greenhouses, which constantly maintain a high temperature [1].

Sometimes during the operation of wood under the conditions of fluctuations in temperature and humidity fields within wide limits, the compositions that are dissolved in 
water are easily washed from the surface of timber. This leads to swelling of structures under the action of moisture and restricts their service life. The application of environmentally friendly substances based on oil requires fundamental research into the impact exerted on the resistance of products by environmental conditions. In addition, the mechanism of protection of wood with coatings against moisture and rotting has not been studied in detail, which makes it impossible to receive objective information about the nature of the processes that occur during operation. And the lack of theoretical ideas about the impact on their resistance of mixtures of antiseptics-hydrophobic agents, which are oils, significantly limits the scale and prospects of using these materials.

Therefore, it is a relevant task to define patterns of inhibiting the process of absorption of water by wood through the shell of a water-resistant (polymeric) coating.

\section{Literature review and problem statement}

Paper [2] reports a study of natural tung, linseed, and soybean oils as coatings of different compositions can inhibit the growth of fungi. Oils were placed under direct sunlight to form a hardened film on maple wood. The chemical composition of the curing and its effect on chemical resistance, water resistance, and thermal stability have been characterized and evaluated using spectroscopy, immersion in the solvent, water contact angle, and thermogravimetric analysis. The oil-covered samples were then placed in Petri dishes with agar, applied with white-rot fungi. The results showed that all oil-based coatings inhibit the growth of fungi, with tung oil being the most effective, followed by linseed and soybean oils. When mixed with a small fraction of tung oil, both linseed and soybean oils demonstrated a curing rate at least twice as fast as individual oils and showed much better inhibition of growth against fungi. This class of green natural oil coatings can be beneficial both economically and socially, given their large number, low cost, and environmental friendliness. However, the durability of such a coating was not determined.

The development of coatings that retain an attractive natural appearance of wood, providing protection against ultraviolet light (UV), is extremely important for widespread use. Paper [3] studies the effect of various types (powdered and water dispersed) $\mathrm{TiO}_{2}$ in the amount of $1.0 \%$ by weight of the monomer on the properties of environmentally friendly emulsions. These include a mixture of polyacrylate (PA) and $\mathrm{TiO}_{2}$ obtained as a result of a polymerization reaction. The results showed that the addition of $\mathrm{TiO}_{2}$ significantly affected the granulometric composition of PA while the viscosity of PA varied depending on the preparation technique. Compared to the sample preparation method, polymerization provides better dispersion of $\mathrm{TiO}_{2}$ nanoparticles in the coating film, as well as a better UV protection effect and greater transparency of the coating film. Better morphology and transparency of nano-coating films have been achieved by adding $\mathrm{TiO}_{2}$ nanofillers in water dispersion compared to the addition of $\mathrm{TiO}_{2}$ in powder form. At the same time, an increase in the bonding temperature during ultraviolet influence was registered, which is associated with the stitching of the polymer. That confirms better UV protection while the photocatalytic effect of $\mathrm{TiO}_{2}$ was more pronounced for manufactured film coating samples. The results suggest that the preparation technique has a significant impact on the properties of the coating film but is characterized by technological complexity.

Silicate coatings are environmentally friendly products on an inorganic basis, which have long been used for mineral substrates and the protection of steel from corrosion [4]. In the cited paper, the adhesion of various silicates-based compositions to the base of beech wood was evaluated with the main purpose of studying the relevant parameters and potential improvements. The strength of adhesion was determined by means of tests for detachment and transverse cutting. Other coating properties have also been identified, such as resistance to scratches, bumps, and water. The roughness of the surface, as well as the interface surface, was analyzed using confocal laser scanning microscopy and electron microscopy; the hardening of the coating was investigated using infrared spectroscopy. The results showed that adhesion depended heavily on formulation, coating penetration into wood, and mechanical fixation. The increase in the content of particulate matter in the composition of coatings or the addition of polyol (glycerin, xylose), which probably acted as a coalescent, significantly reduced the strength of adhesion, likely blocking penetration into the wood by forming aggregates. Adhesion was improved by preliminary mineralization of the surface while the replacement of part of the potassium silicate binder with potassium methyl siliconate reduced the formation of cracks caused by instability in the size of the wood. However, such a coating is rigid and can crumble during operation.

To protect the wood from damage in wet conditions, a reliable aluminum coating has been developed [5]. Thus, readily available alumina was used to create a hard surface, which was then chemically combined with polydimethylsiloxane for the development of hydrophobic characteristics. To provide hydrophobic properties, several layers of substitutes for polydimethylsiloxane were created together with alumina particles; the effect of water on the coating and testing of it with the grinding paper was investigated. Glass substrates and other hydrophilic materials were used to apply the coating. The coated wood, which has superhydrophobic properties, was investigated by distinguishing and changing the contact angle by analyzing the level of water absorption in covered and uncovered wood samples. However, there remained unresolved issues related to the resistance of these coatings to atmospheric fluctuations when used outdoors.

Significant interest arose in environmentally friendly technologies for the protection of wood [6]. The cited study focuses on the development of an environmentally friendly formulation to protect the wood from the pyrolytic distillate of coconut shells. Rubber-bearing wood samples treated with composition were exposed to brown and white rot fungi; the efficacy was evaluated in terms of percentage weight loss and FTIR spectrum analysis. The treated samples showed a significant decrease in weight loss compared to the control samples, indicating the effectiveness of the distillate. FTIR spectra further confirmed the distillate's ability to protect wood from rotting. The main components of the distillate were phenolic compounds, confirmed by chromatographic analysis. The presence of phenolic compounds in the distillate gives the treated wood considerable resistance to rotting against white and brown rot fungi; however, the issue of their resistance to leaching remains unresolved.

Paper [7] describes a new method of wood protection, which is based on titanium isopropoxide gel and cerium nitrate as a stabilizer for wood treatment. Titanium iso- 
propoxide hydrolysis is initiated by $\mathrm{OH}$-groups of wood, as well as moisture in the cell wall of wood, and subsequently leads to the formation of the $\mathrm{TiO}_{2}$ layer alloyed with cerium. This layer not only protects the surface of the wood from the direct influence of hydrolytic enzymes but also clogs the micro and nanopores of wood cells. Cerium nitrate acts as a radical absorber that extinguishes hydroxyl radicals at the initial stage. The $\mathrm{TiO}_{2} / \mathrm{Ce}$ xerogel coating also improves resistance to atmospheric influences as the modified samples have shown good antifungal properties even after accelerated atmospheric exposure. This new method of protecting wood is a greener and safer alternative to traditional biocidal wood preservatives. It has the potential to extend the service life of wood materials, especially for external use, as well as for archaeological preservation of wood. However, the environmental friendliness of the coating was not specified.

The development of nanotechnology makes it possible to achieve further improvements or new operational properties of wood coatings [8]. Increased protection against ultraviolet radiation with nano metal oxides, which allow the texture of wood to remain visible, has been established. At the same time, increased scratch resistance and abrasion with nanoparticles of various shapes are some of the applications discussed here. A variety of possible applications, along with a high level of improvement, as well as commercial factors such as low load levels, have already created nanoparticles in some areas of wood coatings. However, nothing was said about the degradation of the coating during operation.

Study [9] demonstrates an effective and environmentally friendly method that significantly improves the durability of a fiber-based wood composite product by incorporating a natural wood protection system. In particular, allyl isothiocyanate (AITC), a natural biocide based on mustard oil, was encapsulated into the cavity of $\beta$-cyclodextrin $(\beta C D)$; the prepared $\beta C D$-AITC system was used in the production of compositions based on wood chains. The formation of the $\beta C D$-AITC system was qualitatively confirmed by Fourier's infrared spectroscopy, and, according to thermogravimetric analysis, the AITC inclusion yield was estimated at $71 \%$. The preservative system was mixed with southern pine wood at a concentration of $5 \%$ and $10 \%$ before applying polymeric methylene diphenyl diisocyanate resin and hot pressing. The use of the preservative system has significantly improved resistance to rotting against brown rot fungi, keeping the average weight loss of treated panels below $7 \%$. The internal grip strength of the treated panels was maintained above the required level for the structural OSB plate for use under wet conditions. The cited study suggests that the $\beta C D$-AITC system is an alternative to conventional preservatives to protect wood composites; however, no conditions of use have been determined.

Drying oils provide the best protection of timber articles but their use is limited by their long-term polymerization. When studying [10] the drying behavior of linseed oil, tung oil, and their 1:1 mixture, repeated measurements of the angle of contact with water coatings applied to beech and oak wood showed clear differences in wetting. Tung oil rendered hydrophobicity to all wood samples shortly after application, even when used without a dryer. Linseed oil required a longer drying time and was more susceptible to substrate exposure but eventually reached the highest contact angles after forced drying.

When operating timber, its components' biopolymers are subjected to intensive and progressive processes of oxidative degradation under environmental conditions [11]. That affects the natural strength of wood and causes significant structural and color changes, as well as a gradual decrease in its resistance to biological agents. One of the effective ways to prevent timber degradation is to apply protective coating layers by chemically modifying the surface. Recent trends in this area include the use of natural products on a biological base, namely extractive substances, oils, waxes, resins, biopolymers, biological control agents, for which the main criterion of classification is represented by the type of protection. However, there remained unresolved issues related to the resistance of these coatings to atmospheric fluctuations when used outdoors.

Thus, the scientific literature helped us establish that during the operation of wood there is a gradual degradation of components, which requires effective protection with environmentally friendly substances. In addition, there are no defined parameters that provide resistance to loss of protective properties. The lack of mathematical models for explaining and describing the process of bio-protection of wood, neglecting the use of organic substances for the formation of elastic coatings leads to inefficient use of protective agents. Therefore, the task to establish parameters of wood resistance to biodestruction and the impact of coatings on this process has necessitated our research in this area.

\section{The aim and objectives of the study}

The purpose of this work is to identify patterns of inhibition of the process of absorption of water by wood with a protective coating when it is exposed to it. This could make it possible to justify the use of protective coatings at facilities made of timber.

To accomplish the aim, the following tasks have been set:

- to simulate the process of absorption of water by wood through a protective coating;

- to establish the degree of water absorption by wood when protected by a coating of a mixture of oil and paraffin.

\section{The study materials and methods}

\section{1. Research hypothesis}

The object of our research is wood treated with a protective coating that creates a polymer shell on the surface.

The scientific hypothesis assumes a predetermined change in the surface of wood treated with a protective coating that creates a polymer shell on the surface to reduce the degree of absorption of water when changing temperature and humidity fields within wide limits.

\section{2. Materials and equipment used in the experiment}

In the study, we used samples of non-treated hornbeam wood measuring $20 \times 10 \times 10 \mathrm{~mm}$ (Fig. 1)

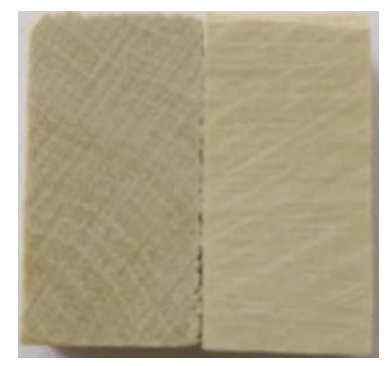

Fig. 1. Model sample of wood 
To establish the degree of absorption of water by wood, we used samples of wood with a protective coating. To this end, we prepared the samples of the protective coating of paraffin, linseed and rapeseed oil, and their mixtures, in the following proportion: $80 \%$ oil and $20 \%$ paraffin; $87.5 \%$ oil and $12.5 \%$ paraffin; $90 \%$ oil and $10 \%$ paraffin; $95 \%$ oil and $5 \%$ paraffin. Paraffin was dissolved in a steam bath; we then added a certain amount of oil and mixed it (Fig. 2).

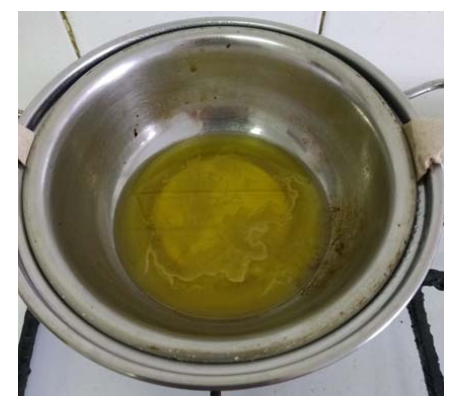

Fig. 2. Preparation of protective coating of oil and paraffin

After cooling to room temperature, the wood samples were coated (Fig. 3). To this end, a protective coating consisting of linseed and rapeseed oil, paraffin, and their mixtures was applied to the surface of the wood with a brush with re-treatment after drying the first layer in 24 hours, with a total consumption of about $148 \mathrm{~g} / \mathrm{m}^{2}$ [12].

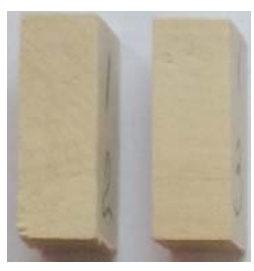

$a$

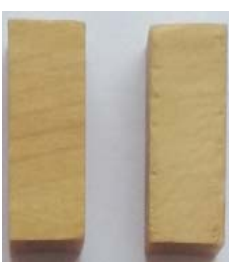

$b$

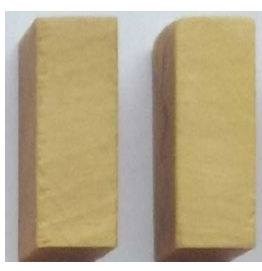

$c$
Fig. 3. Samples for testing hornbeam wood: $a$ - non-treated; $b-$ treated with linseed oil; $c-$ treated with rapeseed oil

After exposure for 2 days, the samples of wood with the resulting protective coating were tested for water absorption.

\section{3. Methodology for determining the indicators of} samples' properties

We determined the degree of absorption of water by wood according to the working procedure, the essence of which was to experimentally determine the amount of water absorbed by the sample during its exposure to water. To obtain the values of water absorbed by the wood, we designed and manufactured special equipment (Fig. 4).

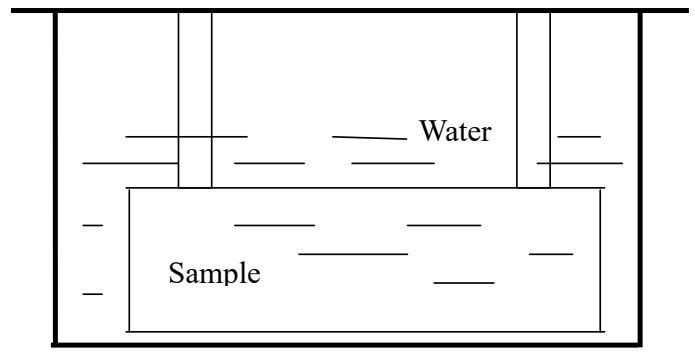

Fig. 4. Device for testing the absorption of water by wood
The test sample was fixed in a special cup so that it was immersed in the water. After a certain period, the sample was weighed on the scales to determine the amount of water absorbed.

Fig. 5 shows the process of immersing wood samples in water for twenty days, at the NUBiP laboratory, Ukraine (Fig. 5).

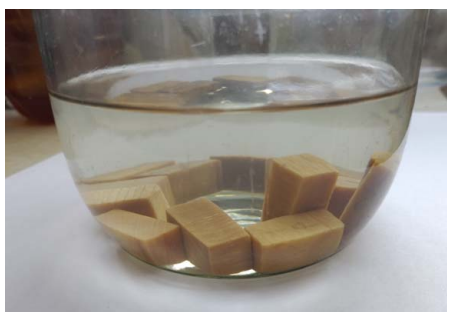

Fig. 5. Immersing wood samples in water

After keeping the samples in water for a set period, we removed excess water from the surface using filter paper and weighed the samples.

\section{Results of studying the process of protection of wood} with a polymer shell before water absorption

5. 1. Modeling the process of absorption of water by wood through a protective coating

The mechanism of operation of the protective coating for wood during operation is as follows: when water enters the wood in the presence of a polymer shell of the protective coating on the surface of the sample, the intensity of absorption of water by wood decreases since the polymer film clogs the pores and trachea of the wood from the penetration of water.

To determine the intensity of water absorption, it was assumed that substance 1 (water) is evenly distributed over the region $-\infty<x<+\infty$ (initial concentration A) [13]. From time $t>0$, substance 1 diffuses into the region $0<x<\infty$ and reacts with substance 2 (wood with an initial concentration B) that does not penetrate the interface. As an interface, we obtain a polymer shell. It is required to find the mass flow rate of substance 1 across the boundary of the region at large values of time $(t>\infty)$.

The differential diffusion equation describing the process of absorption of water by a material [14] is as follows:

$$
\left(\frac{\partial}{\partial t}-D^{*} \frac{\partial^{2}}{\partial x^{2}}\right) C_{1}=0,
$$

where $C$ is the concentration of a substance, \%;

$D^{*}$ - water diffusion coefficient, $\mathrm{m}^{2} / \mathrm{s}$;

$t$ - the time a sample stays in a humid environment, s.

The initial and boundary conditions:

$$
\begin{aligned}
& \left.C_{1}\right|_{x \rightarrow-\infty}=A,\left.C_{1}\right|_{x=\infty}=0,\left.C_{1}\right|_{t=0, \mathrm{x} \prec 0}=A,\left.C_{1}\right|_{t=0, x \succ 0}=0, \\
& \left.C_{2}\right|_{x=\infty}=B,\left.\frac{\partial C_{2}}{\partial x}\right|_{x=0}=0,\left.C_{2}\right|_{t=0, x \succ 0}=B, \\
& \left.\phi C_{1}\right|_{x=0}=\left.C_{1}\right|_{x=0},\left.D^{*} \frac{\partial C_{1}}{\partial x}\right|_{x=0}=\left.D \frac{\partial C_{1}}{\partial x}\right|_{x=0},
\end{aligned}
$$

where $\phi$ is the distribution coefficient.

Given that solving problem (1) necessitates a zero condition $x=-\infty$, the function $A-C_{1}$ was introduced, which made 
it possible to obtain the following dependence taking into consideration [15]:

$$
\frac{\partial^{1 / 2}}{\partial t^{1 / 2}}\left(A-C_{1}\right)-\sqrt{D^{*}} \frac{\partial}{\partial x}\left(A-C_{1}\right)=0
$$

Taking into consideration the boundary conditions (2), the derivative at the interface is removed, then equation (3), which holds for $t>0$, can be represented in the following notation:

$$
\left.C_{2}\right|_{x=0}=\left.\left(\frac{\sqrt{D^{*} / D}}{\phi}+1\right) C_{1}\right|_{x=0}+B-A \cdot \sqrt{D^{*} / D} .
$$

The quantity $\left.C_{2}\right|_{x=0}$ under the condition $t \rightarrow \infty$ tends to a constant value, that is, at high values of time $t$ when the flow of substance 1 at the interface becomes small. The concentration of substance 2 under the condition $x=0$ is set at the initial value $B$, then, from (4), for the condition $t \rightarrow \infty$, we obtain the following dependence:

$$
\left.C_{1}\right|_{x=0}=\frac{\sqrt{D^{*}}}{\phi^{-1} \cdot \sqrt{D^{*}}+\sqrt{D}} A=\text { const. }
$$

The mass flow rate value of substance 1 across the boundary of the interface is found using equations (5) and (3):

$$
\begin{aligned}
& -\left.D^{*} \cdot C_{1}\right|_{x=0}=\sqrt{D^{*}} \frac{\partial^{1 / 2}}{\partial t^{1 / 2}}\left(A-C_{1}\right)= \\
& =\sqrt{D^{*}}\left[\frac{A}{\sqrt{\pi \cdot t}}-\frac{\partial^{1 / 2}}{\partial t^{1 / 2}}\left(\frac{\phi^{-1} \cdot \sqrt{D^{*}}}{\phi^{-1} \cdot \sqrt{D^{*}}+\sqrt{D}} \cdot A+f(t)\right)\right] .
\end{aligned}
$$

Given that the function $f(t) \rightarrow 0$ is descending, at high values of time $t$ the flow of the substance can be expressed by the following equation [16]:

$$
-\left.D^{*} \cdot C_{1}\right|_{x=0}=\frac{\sqrt{D^{*} \cdot D}}{\phi^{-1} \cdot \sqrt{D^{*}}+\sqrt{D}} \cdot \frac{A}{\sqrt{\pi \cdot t}},
$$

at

$$
t \rightarrow \infty \text {. }
$$

It follows that at high time values, the rate of mass exchange is determined only by diffusion when there is no chemical reaction on the surface and is satisfactorily described by the following equation:

$$
-\left.D^{*} \cdot C_{1}\right|_{x=0}=\sqrt{\frac{D^{*}}{\pi \cdot t} \cdot A} .
$$

The resulting equation (8) makes it possible to calculate the intensity of the mass transfer in wood according to the experimental values of the diffusion coefficient and the exposure time of a wood sample.

\section{2. Determining the degree of water absorption by} wood through a polymer shell experimentally

It should also be considered that wood absorbs water during operation, which could cause its swelling and crumpling. Taking into consideration the study reported in [17], in order to protect materials against biological destruction, it is proposed to use natural polymeric materials that can create a polymer shell that prevents the penetration of water when applied to the surface of wood.

Table 1 gives the results of water absorption by a sample after exposure to water for 20 days. Our analysis of the experimental results on water absorption by wood reveals that

\begin{tabular}{|c|c|c|c|c|c|c|c|c|c|}
\hline \multirow{2}{*}{ Coating type } & \multirow{2}{*}{$\begin{array}{c}\text { Mass } \\
\text { after } \\
\text { ap- } \\
\text { plica- } \\
\text { tion, g } \\
\end{array}$} & \multicolumn{8}{|c|}{$\begin{array}{c}\text { Change in the mass of samples in a humic } \\
\text { environment, day }\end{array}$} \\
\hline & & 0.1 & 1 & 2 & 3 & 6 & 9 & 13 & 20 \\
\hline $\begin{array}{c}\text { non-treated } \\
\text { hornbeam }\end{array}$ & 1.64 & 2.12 & 2.40 & 2.44 & 2.46 & 2.48 & 2.53 & 2.58 & 2.76 \\
\hline linseed oil & 1.90 & 2.15 & 2.67 & 2.80 & 2.80 & 2.80 & 2.81 & 2.84 & 2.94 \\
\hline rapeseed oil & 1.92 & 2.23 & 2.84 & 2.95 & 2.95 & 2.94 & 2.96 & 2.96 & 2.99 \\
\hline paraffin & 1.75 & 2.31 & 2.57 & 2.63 & 2.63 & 2.66 & 2.70 & 2.70 & 2.74 \\
\hline $\begin{array}{l}\text { linseed oil }+5 \% \\
\text { paraffin }\end{array}$ & 2.10 & 2.12 & 2.53 & 2.69 & 2.78 & 2.85 & 2.85 & 2.92 & 2.92 \\
\hline $\begin{array}{c}\text { rapeseed oil }+5 \% \\
\text { paraffin }\end{array}$ & 2.09 & 2.10 & 2.51 & 2.66 & 2.75 & 2.79 & 2.83 & 2.89 & 2.89 \\
\hline $\begin{array}{c}\text { linseed oil }+10 \% \\
\text { paraffin }\end{array}$ & 1.98 & 2.04 & 2.47 & 2.72 & 2.75 & 2.78 & 2.83 & 2.85 & 2.86 \\
\hline $\begin{array}{c}\text { rapeseed } \\
\text { oil }+10 \% \\
\text { paraffin } \\
\end{array}$ & 2.05 & 2.10 & 2.67 & 2.82 & 2.84 & 2.84 & 2.92 & 2.95 & 2.96 \\
\hline $\begin{array}{c}\text { linseed } \\
\text { oil+12.5 \% } \\
\text { paraffin }\end{array}$ & 1.87 & 2.00 & 2.36 & 2.57 & 2.59 & 2.67 & 2.77 & 2.82 & 2.83 \\
\hline $\begin{array}{c}\text { rapeseed } \\
\text { oil+12.5\% } \\
\text { paraffin } \\
\end{array}$ & 1.83 & 1.99 & 2.44 & 2.64 & 2.66 & 2.66 & 2.77 & 2.78 & 2.78 \\
\hline $\begin{array}{l}\text { linseed oil }+20 \% \\
\text { paraffin }\end{array}$ & 1.87 & 2.02 & 2.49 & 2.67 & 2.69 & 2.71 & 2.82 & 2.85 & 2.87 \\
\hline $\begin{array}{c}\text { rapeseed } \\
\text { oil }+20 \% \\
\text { paraffin }\end{array}$ & 1.91 & 2.11 & 2.60 & 2.76 & 2.77 & 2.77 & 2.88 & 2.90 & 2.92 \\
\hline
\end{tabular}
the maximum increase in mass in the case of water absorption by an untreated sample of wood was $40 \%$, and the increase in the mass of wood samples treated with mixtures of oil and paraffin was less than $28 \%$.

Table 1

Results of studying the impact of the protective coating on the resistance of wood to water absorption

Based on the results of experimental studies (Table 1), we established the nature of water absorption by wood through the polymer shell, which was created with different ratios of oil mixed with paraffin: it is shown in Fig. 6.

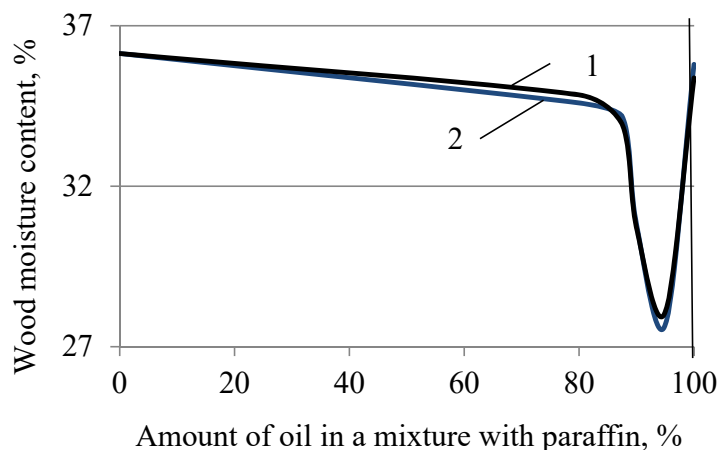

Fig. 6 . The nature of water absorption by wood through a polymer shell, which was created with different ratios of oil mixed with paraffin: 1 - linseed, 2 - rapeseed 
Fig. 6 demonstrates that both linseed oil 1 and rapeseed oil 2 produced the same result as they effectively cover the wood and create a shell that inhibits the penetration of water into the wood. The best protection is shown by a mixture of oil and paraffin within $90 \div 95 \%$; at these values, the moisture content of wood did not exceed $28 \%$. At oil values of up to $80 \%$, the mixture of paraffin and oil is characterized by very high density and low fluidity and is difficult to apply to wood.

According to the procedure given in [18], the coefficients of diffusion of moisture were calculated; equation (8) was used to determine the intensity of the mass transfer in wood; the values are given in Table 2 .

Table 2

Values of the diffusion coefficient and the intensity of mass transfer when wood absorbs water

\begin{tabular}{|c|c|c|}
\hline \multirow{2}{*}{ Coating type } & \multicolumn{2}{|c|}{ Indicator } \\
\cline { 2 - 3 } & $\begin{array}{c}\text { moisture diffu- } \\
\text { sion coefficient, } \\
\times 10^{-8} \mathrm{~m}^{2} / \mathrm{s}\end{array}$ & $\begin{array}{c}\text { intensity of } \\
\text { mass transfer, } \\
\times 10^{-6} \mathrm{~m} / \mathrm{s}\end{array}$ \\
\hline non-treated hornbeam & 0.753 & 110.00 \\
\hline linseed oil & 0.046 & 27.1 \\
\hline rapeseed oil & 0.048 & 27.6 \\
\hline paraffin & 0.133 & 46.0 \\
\hline linseed oil+5\% paraffin & 0.0021 & 5.78 \\
\hline rapeseed oil+5\% paraffin & 0.0020 & 5.64 \\
\hline linseed oil+10\% paraffin & 0.0054 & 9.27 \\
\hline rapeseed oil+10\% paraffin & 0.0056 & 9.44 \\
\hline linseed oil+12.5\% paraffin & 0.011 & 13.2 \\
\hline rapeseed oil+12.5\% paraffin & 0.012 & 13.8 \\
\hline linseed oil+20\% paraffin & 0.034 & 23.3 \\
\hline rapeseed oil+20\% paraffin & 0.033 & 22.9 \\
\hline
\end{tabular}

It has been established that the use of coating from a mixture of oil and paraffin on the surface of an article reduces the process of diffusion of moisture and the intensity of water mass transfer by more than 10 times. Such a coating greatly prolongs the service life of timber and allows its use at facilities with high humidity.

\section{Discussion of results of studying the process of absorption of water by wood through a polymer shell}

When studying the process of reducing the level of absorption of water by wood while applying a protective coating, it follows from our results (Tables 1, 2, Fig. 6) that the inhibition of the time of penetration of water through a protective coating is natural. This is due to the formation of a protective shell on the surface of the wood during the polymerization of the mixture of oil and paraffin, which slows down the processes of water penetration into wood and its subsequent destruction.

It should be noted that the presence of a polymer shell of oil and paraffin leads to the formation of an elastic film resistant to water penetration on the surface of timber. Such a mechanism of influence of an elastic film is likely the factor in regulating the process by which the resistance of wood to water absorption is maintained. In this sense, there is an interpretation of the results of determining the water absorption by wood after exposure to water, namely the increase in the mass of samples after exposure to water. The degree of absorption of water by wood protected by mixtures of oil and paraffin did not exceed $28 \%$; for a sample of ordinary wood amounted to more than $40 \%$. This indicates the formation of a barrier for the penetration of water, which can be identified by the method of water exposure to the samples under study.

Taking this fact into consideration opens the possibility for effective adjustment of wood properties directly under the conditions of industrial production.

Our comparison of experimental studies into the absorption of water by wood when applying a protective coating and the theoretical research on determining the mass transfer indicates inhibition of water penetration processes. The humidity of the protected wood did not exceed $28 \%$.

This does not diverge from the practical data reported in $[6,7]$, whose authors also associate the effectiveness of protection with the formation of a protective shell on the surface of the wood. However, unlike the results given in $[8,9]$, our data on the effect of the protective coating on the process of inhibition of water penetration suggest the following:

- the main regulator of the process is not so much the formation of a significant amount of coating that inhibits water absorption since individual protective coatings are destroyed under the influence of atmospheric action;

- a significant impact on the process of wood protection when using a protective coating is exerted towards the formation of a shell of an elastic film on the surface of the material resistant to destruction under the influence of fluctuations in temperature and humidity fields.

Such conclusions should be considered appropriate from a practical point of view because they allow for a reasonable approach to determining the required amount of protective agents. From a theoretical point of view, that allows us to assert the determination of the mechanism of the processes of inhibition of water permeability, which is an advantage of the current study.

However, it should be noted that the results shown in Fig. 5 indicate an ambiguous impact of the coating on changes in protective effectiveness. This is manifested, first of all, by the increase in the mass of the sample during tests of wood protected by paraffin. Such uncertainty imposes certain restrictions on the use of the results obtained, which can be interpreted as a shortcoming of our study. The inability to remove these restrictions in the framework of this study points to a potentially interesting direction of further research. In particular, it can be focused on identifying the moment when the reduction of protective properties begins before the absorption of water by wood. Such detection would make it possible to investigate the structural transformations of the elastic film that begin to occur at this time and to determine the input variables of the process that significantly affect the onset of such a transformation.

\section{Conclusions}

1. We have proposed a method for determining the rate of mass exchange, which is based on an analytical procedure to solve the differential diffusion equation. This makes it possible, given its simplicity (unlike numerical), to find concentration flows at the interface of two substances directly according to the coefficients of the original equation and boundary conditions. Based on the analytical data and the derived dependences, we have calculated the intensity of 
mass transfer of water to wood, which corresponds to a value of more than 20 times less than without coating.

2. Features of inhibition of the process of penetration of water into the material treated with a composition based on oil and paraffin are the formation of a stable elastic protective layer on the surface of the wood. Thus, a polymer shell was created on the surface of the sample, which significantly reduced the penetration of water into wood while the increase in the mass of wood under the influence of water did not exceed $28 \%$.

\section{Acknowledgments}

We express our gratitude for the financial support to this work carried out within the framework of budget No.0121U001007, as well as for the development of scientific topics in the COST Action FP 1407 scientific cooperation program "Elucidating wood modification through an integrated scientific and environmental approach" within the framework of the European Union's HORIZON2020 program.

\section{References}

1. Kiktev, N., Lendiel, T., Vasilenkov, V., Kapralyuk, O., Hutsol, T., Glowacki, S. et. al. (2021). Automated Microclimate Regulation in Agricultural Facilities Using the Air Curtain System. Sensors, 21 (24), 8182. doi: https://doi.org/10.3390/s21248182

2. Tang, C. C., Li, Y., Buzoglu Kurnaz, L., Li, J. (2021). Development of eco-friendly antifungal coatings by curing natural seed oils on wood. Progress in Organic Coatings, 161, 106512. doi: https://doi.org/10.1016/j.porgcoat.2021.106512

3. Zeljko, M., Ocelić Bulatović, V., Špada, V., Blagojević, S. L. (2021). Environmentally Friendly UV-Protective Polyacrylate/ $\mathrm{TiO}_{2}$ Nanocoatings. Polymers, 13 (16), 2609. doi: https://doi.org/10.3390/polym13162609

4. Cheumani Yona, A. M., Žigon, J., Dahle, S., Petrič, M. (2021). Study of the Adhesion of Silicate-Based Coating Formulations on a Wood Substrate. Coatings, 11 (1), 61. doi: https://doi.org/10.3390/coatings11010061

5. Moria, H. (2019). Design development and characterization super hydrophobic surface coating on wood materials. International Journal of Advanced Research in Engineering \& Technology, 10 (5). doi: https://doi.org/10.34218/ijaret.10.5.2019.008

6. Shiny, K. S., Sundararaj, R., Vijayalakshmi, G. (2017). Potential use of coconut shell pyrolytic oil distillate (CSPOD) as wood protectant against decay fungi. European Journal of Wood and Wood Products, 76 (2), 767-773. doi: https://doi.org/10.1007/ s00107-017-1193-8

7. Guo, H., Bachtiar, E. V., Ribera, J., Heeb, M., Schwarze, F. W. M. R., Burgert, I. (2018). Non-biocidal preservation of wood against brown-rot fungi with a $\mathrm{TiO}_{2} /$ Ce xerogel. Green Chemistry, 20 (6), 1375-1382. doi: https://doi.org/10.1039/c7gc03751a

8. Nikolic, M., Lawther, J. M., Sanadi, A. R. (2015). Use of nanofillers in wood coatings: a scientific review. Journal of Coatings Technology and Research, 12 (3), 445-461. doi: https://doi.org/10.1007/s11998-015-9659-2

9. Cai, L., Lim, H., Kim, Y., Jeremic, D. (2020). $\beta$-Cyclodextrin-allyl isothiocyanate complex as a natural preservative for strand-based wood composites. Composites Part B: Engineering, 193, 108037. doi: https://doi.org/10.1016/j.compositesb.2020.108037

10. Arminger, B., Jaxel, J., Bacher, M., Gindl-Altmutter, W., Hansmann, C. (2020). On the drying behavior of natural oils used for solid wood finishing. Progress in Organic Coatings, 148, 105831. doi: https://doi.org/10.1016/j.porgcoat.2020.105831

11. Teacă, C.-A., Roşu, D., Mustaţă, F., Rusu, T., Roşu, L., Roşca, I., Varganici, C.-D. (2019). Natural bio-based products for wood coating and protection against degradation: A Review. BioResources, 14 (2), 4873-4901. doi: https://doi.org/10.15376/biores.14.2.teaca

12. Tsapko, Y., Horbachova, O., Mazurchuk, S., Bondarenko, O. (2021). Study of resistance of thermomodified wood to the influence of natural conditions. IOP Conference Series: Materials Science and Engineering, 1164 (1), 012080. doi: https:// doi.org/10.1088/1757-899x/1164/1/012080

13. Tsapko, Y., Vasylyshyn, R., Melnyk, O., Lomaha, V., Tsapko, A., Bondarenko, O. (2021). Regularities in the washing out of watersoluble phosphorus-ammonium salts from the fire-protective coatings of timber through a polyurethane shell. Eastern-European Journal of Enterprise Technologies, 2 (10 (110)), 51-58. doi: https://doi.org/10.15587/1729-4061.2021.229458

14. Tsapko, Y., Sirko, Z., Vasylyshyn, R., Melnyk, O., Tsapko, A., Bondarenko, O., Karpuk, A. (2021). Establishing patterns of mass transfer under the action of water on the hydrophobic coating of the fire-retardant element of a tent. Eastern-European Journal of Enterprise Technologies, 4 (10 (112)), 45-51. doi: https://doi.org/10.15587/1729-4061.2021.237884

15. Janna, W. S. (2018). Engineering Heat Transfer. CRC Press, 692. doi: https://doi.org/10.1201/9781439883143

16. Potter, M. C. (2019). Engineering analysis. Springer, 434. doi: https://doi.org/10.1007/978-3-319-91683-5

17. Tsapko, Y., Horbachova, O., Mazurchuk, S., Tsapko, A., Sokolenko, K., Matviichuk, A. (2021). Determining patterns in reducing the level of bio-destruction of thermally modified timber after applying protective coatings. Eastern-European Journal of Enterprise Technologies, 5 (10 (113)), 48-55. doi: https://doi.org/10.15587/1729-4061.2021.242899

18. Tsapko, Y. V., Horbachova, O. Y. (2021). Establishment of moisture diffusion regularities through the polymer shell of thermally modified wood. Ukrainian Journal of Forest and Wood Science, 12 (1), 41-47. doi: https://doi.org/10.31548/forest2021.01.005 